UNIVERSIDADE DE SÃO PAULO

ESCOLA DE EDUCAÇÃO FÍSICA E ESPORTE

ALTERAÇÕES DA CONCENTRAÇÃO PLASMÁTICA DE LEPTINA E SUA ASSOCIAÇÃO COM A INSULINA: EFEITOS DO TREINAMENTO AERÓBIO CRÔNICO EM RATOS

Fabiana Braga Benatti 


\title{
ALTERAÇÕES DA CONCENTRAÇÃO PLASMÁTICA DE LEPTINA E SUA ASSOCIAÇÃO COM A INSULINA: EFEITOS DO TREINAMENTO AERÓBIO CRÔNICO EM RATOS
}

\author{
FABIANA BRAGA BENATTI
}

Dissertação apresentada à Escola de Educação Física e Esporte da Universidade de São Paulo, como requisito parcial para obtenção do grau de Mestre em Educação Física. 


\section{AGRADECIMENTOS}

Ao Prof. Dr. Antonio Herbert Lancha Junior, pela oportunidade, amizade, pelo constante incentivo e apoio, além da confiança depositada no trabalho.

Aos meus pais, Juliano e Rita, por terem sido um modelo de perseverança, união e honestidade, por serem minha fortaleza, pelo amor e confiança incondicionais, por estarem presentes em todos os momentos, sejam eles de tristezas ou de alegrias e conquistas, acima de tudo me apoiando com muito carinho.

Aos meus irmãos, Bruno e Fernanda, por estarem sempre prontos a me auxiliar e apoiar frente a qualquer obstáculo, com muito carinho, amor e, acima de tudo, por conseguirmos manter essa união inabalável, que me dá muita força e confiança.

Ao Renê, meu namorado querido, o contador que mais conhece sobre leptina, por toda a ajuda, paciência, confiança, por estar sempre ao meu lado, por ser meu companheiro, por ser capaz de me fazer sorrir e de me amparar nas horas tristes, sempre me incentivando e, acima de tudo, com muito amor e carinho.

A toda a minha família, em especial à minha avó querida, por todo afeto e carinho.

À Fapesp, pelo apoio financeiro.

Aos amigos do coração, Kavita Hamza, Renata Amaral, Karina Ribeiro e Danilo Lemos, pela torcida, por todo carinho e amor e por muitas e muitas risadas.

Às amigas, Viviane Polacow, Fernanda Scagliusi, Patrícia Rogeri e Desire Coelho, por todo o apoio, ajuda, conselhos e por todos os momentos divertidos proporcionados em todos esses anos.

A todos os colegas de laboratório, André Costa, Hamilton Hoschel, Patrícia Campos, Patrícia Vieira, Guilherme Artioli, Thiago Onofre, Patrícia Berbel, Bruno Gualano, Rafael Batista, Marco Leme, Luciana Pereira, Rodrigo Moriglia e 
Carolina Morales, além dos novos membros que agora chegam, sempre dispostos a contribuir.

À Prof. Dra. Sandra Maria Lima Ribeiro, pelas dicas, pela ajuda e apoio incondicionais, sempre com muita boa vontade, no momento em que mais precisei, tornando possível a realização deste trabalho.

À Prof. Dra. Marília Cerqueira Leite Seelaender e a todos os membros do Laboratório de Metabolismo Lipídico, do Instituto de Ciências Biomédicas, em especial à Daniela Caetano e ao Fábio Lira (Fio), por terem aberto as portas para que muitas dosagens e análises pudessem ser realizadas, sempre com muita boa vontade e prazer de ensinar.

Ao Prof. Dr. Luiz Fernando Bicudo Costa Rosa (in memoriam), por ceder o espaço e a estrutura de seu laboratório, sem nunca hesitar, e pelos membros do Laboratório de Metabolismo, do Instituto de Ciências Biomédicas, por todo conhecimento e auxílio.

À Prof. Dra. Taís Tinucci, pelas sugestões que enriqueceram o trabalho.

Aos funcionários da Secretaria de Pós-Graduação, Lourdes, Márcio e Ilza.

À Shirley, secretária do Departamento de Biodinâmica, por toda a ajuda e paciência.

A todos os funcionários da Escola de Educação Física e Esporte, em especial à Lúcia, funcionária da biblioteca, e à Camila, funcionária da Comissão de Ética e Pesquisa da EEFE-USP, por todo o auxílio.

Aos amigos da equipe de voleibol da EEFE-USP, pela amizade, por toda a torcida, e por muitos momentos divertidos durante esses anos.

A minha família e a todos aqueles que de alguma forma contribuíram para a realização deste trabalho, por todo carinho e apoio profissional e emocional.

A Deus, por me mostrar novos caminhos a serem seguidos, sempre me fazendo ser uma pessoa melhor. 
SUMÁRIO

Página

LISTA DE TABELAS ..................................................................... vii

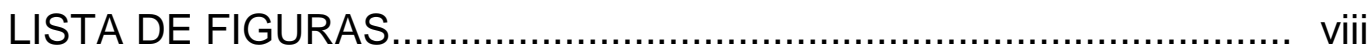

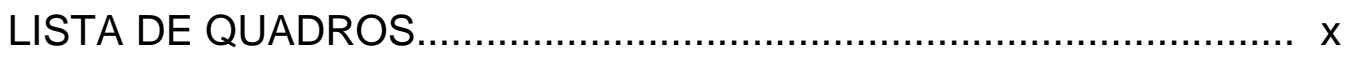

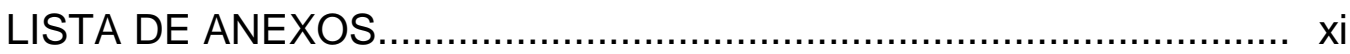

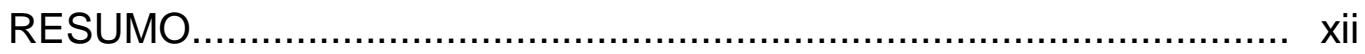

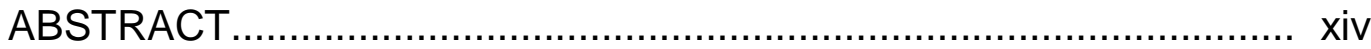

1 INTRODUÇÃO

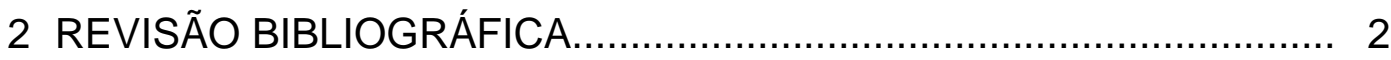

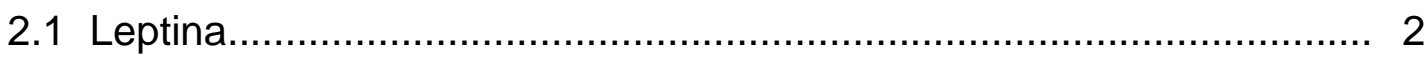

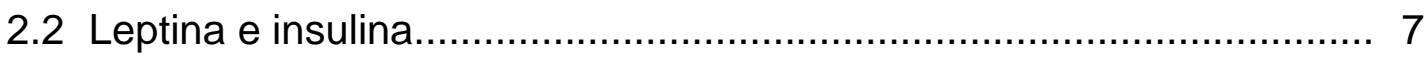

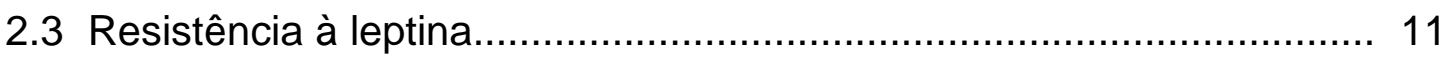

2.4 Leptina e exercício físico.......................................................... 12

3 JUSTIFICATIVA........................................................

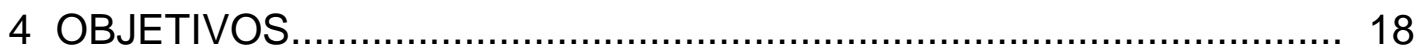

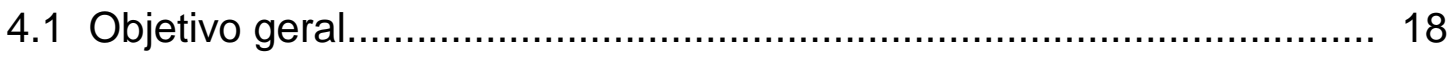

4.2 Objetivos específicos..................................................................... 18

5 MATERIAIS E MÉTODOS................................................................ 18

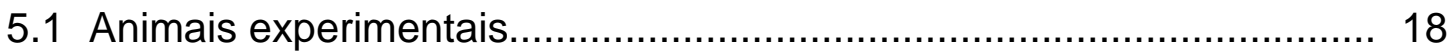

5.2 Protocolo de treinamento dos animais............................................ 19

5.3 Desenho experimental................................................................ 19

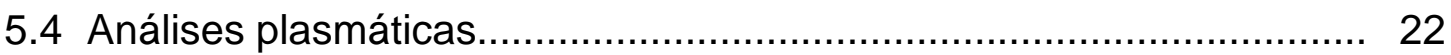

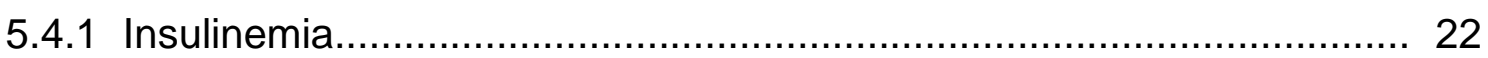

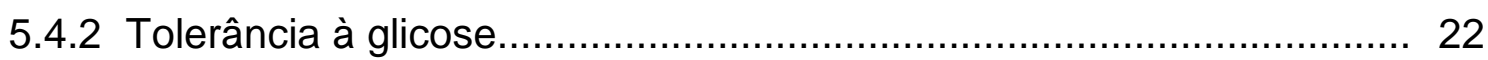

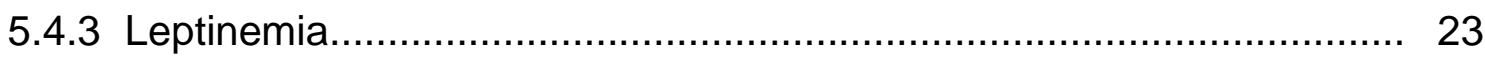

5.5 Conteúdo de gordura corporal........................................................ 23 
5.6 Expressão gênica da leptina................................................... 24

5.7 Gasto energético de repouso................................................... 26

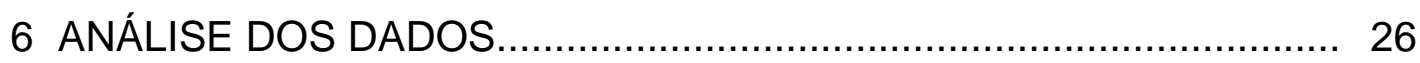

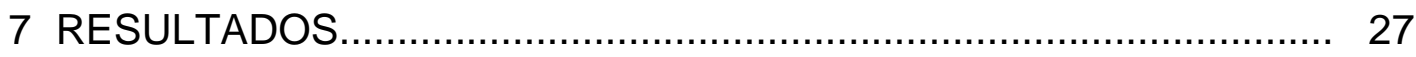

7.1 Peso corporal........................................................................ 27

7.2 Consumo energético.............................................................. 28

7.3 Conteúdo de gordura corporal total............................................ 29

7.4 Curvas glicêmicas.................................................................. 29

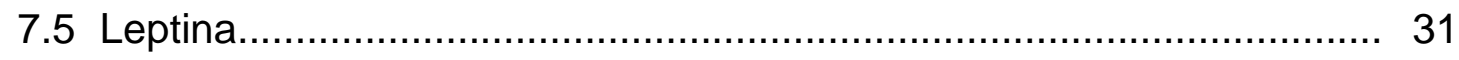

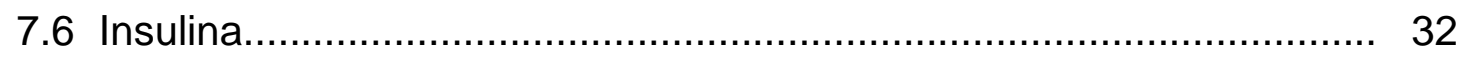

7.7 Gasto energético de repouso...................................................... 33

7.8 Expressão do mRNA da leptina................................................... 34

7.9 Cálculos de correlação e regressão................................................... 35

7.10 Leptina / conteúdo de gordura corporal...................................... 37

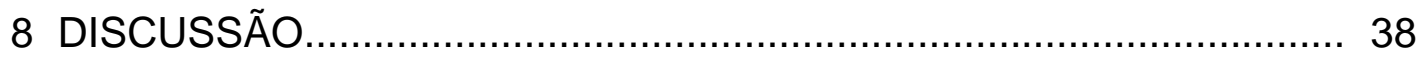

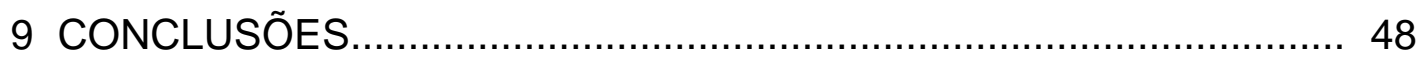

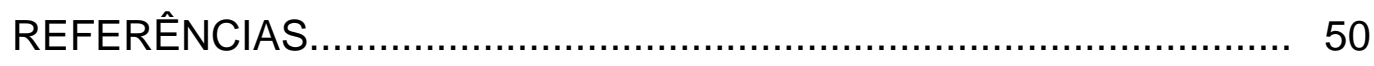

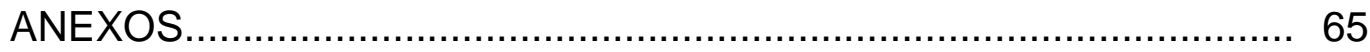




\section{LISTA DE TABELAS}

Página

TABELA 1 - Glicemia (mg/dL) a cada 30 minutos do teste oral de tolerância à glicose (OGTT) e área sob a curva obtida neste teste ao início (semana 0) e ao final (semana 9) do experimento segundo grupo experimental (média \pm desvio padrão); Grupo $T(n=8)$; Grupo $C$ $(n=10) ;{ }^{*}: p<0,05$ em relação ao Grupo $C$ para o mesmo intervalo de tempo; \#: $p<0,05$ em relação à Semana 0 dentro do mesmo grupo experimental..

TABELA 2 - Análise de correlação entre leptina, peso (Semana 9), conteúdo de gordura da carcaça e insulina. 


\section{LISTA DE FIGURAS}

Página

FIGURA 1 - Consumo médio de ração expresso em g ração/g peso corporal segundo grupo experimental (média \pm desvio padrão). Grupo T $(\mathrm{n}=5)$; Grupo $\mathrm{C}(\mathrm{n}=5)$

FIGURA 2 - Evolução do peso corporal (média) ao longo do experimento segundo grupo experimental; Grupo T $(n=18)$; Grupo $C(n=20)$; *: $p<0,05$ entre grupos na mesma semana de avaliação.

FIGURA 3 - Consumo médio de ração (média \pm desvio padrão) segundo grupo experimental; Grupo T ( $n=18)$; Grupo C ( $n=20)$.

FIGURA 4 - Conteúdo (média \pm desvio padrão) de gorduras extraídas das carcaças dos animais segundo grupo experimental; Grupo T $(n=8)$; Grupo $C(n=10) ;{ }^{*}$ : $p<0,05$ entre grupos

FIGURA 5 - Glicemia (média) ao longo dos 120 minutos do teste oral de tolerância ao início (semana 0) e ao final do experimento (semana 9) segundo grupo experimental; Grupo $T(n=8)$; Grupo $C(n=10)$; *: $p<0,05$ entre grupos para o mesmo intervalo de tempo.

FIGURA 6 - Concentração de leptina plasmática (média \pm desvio padrão) segundo grupo experimental; Grupo T ( $n=8)$; Grupo C ( $n=10)$; *: $p<0,05$ entre grupos.

FIGURA 7 - Concentração de insulina plasmática (média \pm desvio padrão) segundo grupo experimental; Grupo T ( $n=8)$; Grupo C ( $n=10)$; *: $p<0,05$ ente grupos.

FIGURA 8 - Consumo de oxigênio em repouso (média \pm desvio padrão) segundo grupo experimental; Grupo T ( $n=10)$; Grupo C $(n=10) \ldots . .34$ 
FIGURA 9 - Expressão da leptina no TAV e TAS (média \pm desvio padrão) segundo grupo experimental; Grupo T (n=4); Grupo C (n=4); *: $\mathrm{p}<0,05$ em relação ao TAS do mesmo grupo

FIGURA 10 - Análise representativa da expressão gênica no tecido adiposo visceral (TAV) e tecido adiposo subcutâneo (TAS) segundo grupo experimental.

FIGURA 11 - Relação entre o conteúdo de gordura da carcaça e concentração de leptina.

FIGURA 12 - Concentração de leptina plasmática / conteúdo lipídico total (média \pm desvio padrão) segundo grupo experimental; Grupo T $(n=8)$; Grupo $C(n=10) ;{ }^{*}: p<0,05$ ente grupos. 


\section{LISTA DE QUADROS}

Página

QUADRO 1 - Treinamento segundo grupo experimental...................................... 19

QUADRO 2 - Cronograma dos experimentos realizados................................... 21 


\section{LISTA DE ANEXOS}

Página

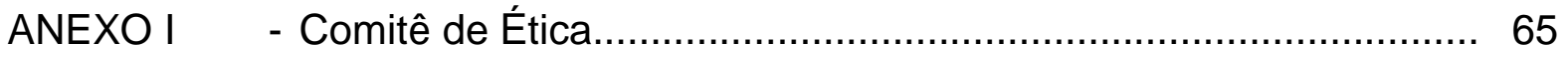




\title{
RESUMO
}

\section{ALTERAÇÕES DA CONCENTRAÇÃO PLASMÁTICA DE LEPTINA E SUA ASSOCIAÇÃO COM A INSULINA: EFEITOS DO TREINAMENTO AERÓBIO CRÔNICO EM RATOS}

\author{
Autor: FABIANA BRAGA BENATTI \\ Orientador: PROF.DR. ANTONIO HERBERT LANCHA JUNIOR
}

Atualmente, a obesidade pode ser classificada como uma pandemia. Com a clonagem do gene ob e do seu receptor, foi descoberta a leptina. Secretada principalmente pelo tecido adiposo, está diretamente correlacionada à quantidade de gordura corporal. Entretanto, diversos fatores influenciam sua expressão e síntese, tais como jejum, atividade simpática, exercício físico e alterações no balanço energético. Os efeitos do treinamento aeróbio sobre este hormônio são ainda contraditórios. Desta forma, este estudo teve como objetivo a verificação dos efeitos do treinamento aeróbio nas concentrações plasmáticas de leptina. Ratos Wistar machos foram divididos em dois grupos: treinado (T) e controle (C). Não houve diferença na ingestão energética e no gasto energético de repouso. Ratos treinados apresentaram menor peso corporal final, conteúdo de gordura corporal, insulinemia e melhora na resposta glicêmica. Houve maior expressão do mRNA da leptina no tecido adiposo visceral do que no subcutâneo nos dois grupos. Não houve, entretanto, diferença na expressão da leptina entre os grupos em ambos os depósitos. A menor concentração de leptina plasmática nos animais treinados ocorreu, principalmente, devido ao menor conteúdo de gordura corporal deste grupo. No entanto, após a correção da concentração de 
leptina pelo conteúdo de gordura corporal, ainda foi observada diferença significativa entre os grupos, sugerindo que exista(m) outro(s) fator(es) de modulação das concentrações de leptina após o treinamento aeróbio, sendo a principal candidata a tal regulação a insulina.

Palavras-chave: treinamento aeróbio, leptina, tecido adiposo, insulina. 


\title{
ABSTRACT
}

\section{CHANGES IN LEPTIN LEVELS AND ITS ASSOCIATION WITH INSULIN: EFFECTS OF CHRONIC ENDURANCE TRAINING IN RATS}

\author{
Author: FABIANA BRAGA BENATTI \\ Adviser: PROF.DR. ANTONIO HERBERT LANCHA JUNIOR
}

Obesity currently qualifies as a worldwide health epidemic. With the cloning of mouse ob gene and its receptor leptin was discovered. Leptin is expressed and secreted primarily by adipose tissue and is highly correlated to body fat mass. Nevertheless many factors can regulate leptin synthesis and expression, such as fasting, sympathetic activity, insulin, exercise and changes in energy balance. Endurance training effects on leptin are still contradictory. Therefore the aim of the present study was to verify the effects of endurance training on leptin levels. Male Wistar rats were separated in two groups: trained $(\mathrm{T})$ and sedentary control (C). Energy intake and basal energy expenditure were not different between groups. Trained rats had lower final body weight, body fat mass, insulin levels and improved glycemic response. Leptin mRNA expression was higher in visceral than in subcutaneous adipose tissue in both groups. However, no difference in leptin expression between groups in either fat depot was found. Lower leptin levels in trained rats were due primarily to their lower body fat mass. Nonetheless, after correction for body fat mass leptin levels were still lower in exercised rats, suggesting that there might be other regulators of leptin levels in response to endurance training, being insulin the main candidate for such role.

Keywords: physical training, leptin, adipose tissue, insulin 
